\title{
Caracterização florística e fitossociológica do componente lenhoso de um fragmento florestal de Caatinga em Serra do Mel, Rio Grande do Norte, Brasil
}

\author{
Mary Regina de SOUZA ${ }^{*}$, Maria Beatriz FERREIRA², Geovana Gomes de SOUSA², \\ Allyson Rocha ALVES ${ }^{1,2}$, Alan Cauê de HOLANDA ${ }^{1}$
}

\begin{abstract}
${ }^{1}$ Departamento de Ciências Agronômicas e Florestais, Universidade Federal Rural do Semi-Árido, Mossoró, RN, Brasil. (ORCID: *; 0000-0002-5066-4900; 0000-0003-1408-0075)

${ }_{2}^{2}$ Programa de Pós-Graduação em Ciências Florestais, Universidade Federal de Campina Grande, Patos, PB, Brasil. (ORCID: 0000-0003-4730-2287; 0000-0003-0915-3575;)

*E-mail: maryrsouz@yahoo.com.br (ORCID: 0000-0002-4292-3116)
\end{abstract}

Recebido em 01/10/2019; Aceito em 11/04/2020; Publicado em 24/04/2020.

\begin{abstract}
RESUMO: A caatinga apresenta uma diversidade de fisionomias e um enorme quadro de degradação, sendo importantes os estudos relacionados a fitossociologia para a caracterização da vegetação. O objetivo deste trabalho foi realizar um estudo de florística e fitossociologia em um fragmento florestal de caatinga no município de Serra do Mel no Rio Grande do Norte. Para realização do estudo foi realizado um levantamento da vegetação adotando-se a Amostragem Inteiramente Aleatória, onde foram marcadas 10 unidades amostrais de $20 \times 20 \mathrm{~m}\left(400 \mathrm{~m}^{2}\right)$. Foram amostrados todos os indivíduos florestais arbustivos-arbóreos vivos com CAP $\geq 6 \mathrm{~cm}$. Foram avaliados todos os parâmetros fitossociológicos da estrutura horizontal e vertical, a diversidade florística das espécies através do Índice de Shannon-Weaver (H'), dominância de Simpson (C) e equabilidade de Pielou (J'). No levantamento foram encontradas 7 famílias, 12 gêneros e 12 espécies. As famílias com maior número de espécies e de indivíduos foram a Fabaceae e Euphorbiaceae. Croton blanchetianus, Mimosa tenuiflora, Baubinia forficata, Mimosa ophthalmocentra e Poincianella pyramidalis foram as espécies que assumiram maior importância na área de estudo sob os aspectos fitossociológicos. A área do presente estudo apresenta baixa diversidade de espécies se comparada com outros fragmentos florestais de caatinga já estudados.
\end{abstract}

Palavras-chave: Estrutura; Diversidade; Caatinga.

\section{Floristic-phytosociological characterization of the woody component in a Caatinga fragment in Serra do Mel, Rio Grande do Norte, Brazil}

\begin{abstract}
The caatinga presents a diversity of physiognomies and a huge degradation picture, being important the studies related to phytosociology for the characterization of the vegetation. The aim of this work was to carry out a floristic and phytosociological study in a forest fragment of caatinga in Serra do Mel, Rio Grande do Norte. To carry out the study, a survey of the vegetation was performed adopting the Random Sampling, where 10 sample units of $20 \times 20 \mathrm{~m}\left(400 \mathrm{~m}^{2}\right)$ were marked. All living shrubby-arboreal forest individuals with CAP $\geq 6 \mathrm{~cm}$ were sampled. All phytosociological parameters of horizontal and vertical structure, floristic diversity of species was evaluated through Shannon-Weaver Index $\left(\mathrm{H}^{\prime}\right)$, Simpson dominance (C) and Pielou equability (J'). The analytic survey found 7 families, 12 genera and 12 species. The families with the largest number of species and individuals were Fabaceae and Euphorbiaceae. Croton blanchetianus, Mimosa tenuiflora, Baubinia forficata, Mimosa ophthalmocentra and Poincianella pyramidalis were the most important species in the study area under phytosociological aspects. The area of the present study presents low species diversity compared to other forest fragments of caatinga already studied.
\end{abstract}

Keywords: Phytosociology; diversity; Caatinga.

\section{INTRODUÇÃO}

O Bioma Caatinga representa importante papel socioeconômico para o Nordeste brasileiro, ocupa uma área de aproximadamente $826.411 \mathrm{~km}^{2}$ ocorrendo em todos os estados do Nordeste, e $2 \%$ do estado de Minas Gerais (MMA, 2010).

As paisagens apresentam alta diversidade nos tipos de vegetação encontradas, devido as variações edafoclimaticas que refletem na distribuição, riqueza e diversidade de espécies, como herbáceas, arbustivas e arbóreas com espinhos e presença de caducifólia (ARAÚJO FILHO, 2013).

Atividades realizadas inadequadamente nas áreas de caatinga, intensifica a degradação dos recursos naturais. Isso deve-se à crescente demanda por matéria prima de origem florestal, ocasionando a infertilidade e compactação dos solos, acelerando processos erosivos, salinização dos solos e principalmente a redução da biodiversidade (BRASILEIRO, 2009). 
Os estudos relacionados a análise da vegetação no Nordeste, tem como o objetivo estabelecer os padrões vegetacionais, caracterizando a composição florística atual e a fitossociologia de diferentes formações, relacionando os fatores ambientais com as características da estrutura da vegetação (RODAL et al., 1992).

Dessa forma, justifica-se o estudo sobre composição florística e a fitossociologia das florestas, que é de fundamental importância para o conhecimento da estrutura e da dinâmica, sendo aspectos relevantes para o manejo adequado das florestas (CHAVES et al., 2013).

Estes são imprescindíveis para o conhecimento básico de uma determinada vegetação, o que poderá favorecer e melhorar a tomada de decisão em relação ao destino da utilização dos seus recursos naturais, fazendo com que, torne possível uma exploração racional e a conservação dos componentes encontrados na área.

Com isso, o presente estudo teve como objetivo avaliar a florística e a fitossociologia em uma área de caatinga no município de Serra do Mel no Rio Grande do Norte.

\section{MATERIAL E MÉTODOS}

\section{1. Área de estudo}

O estudo foi realizado em um fragmento de 16,40 ha que está localizado no município de Serra do Mel, Estado do Rio Grande do Norte situado na zona homogênea de Mossoró. $\mathrm{O}$ fragmento está situado entre as coordenadas geográficas $\mathrm{S}$ $5^{\circ} 09^{\prime} 54,5^{\prime \prime}$ e W $37^{\circ} 11^{\prime} 00,5^{\prime}$ "no Município de Serra do Mel (Figura 1).

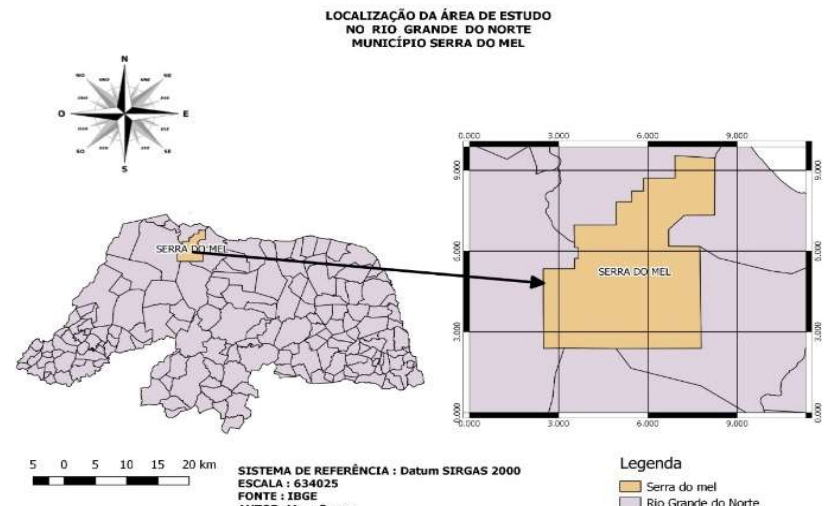

Figura 1. Localização do município de Serra do Mel, Rio Grande do Norte, Brasil.

Figure 1. Location of the municipality of Serra do Mel, Rio Grande do Norte, Brazil.

O clima do município é o semiárido, com ocorrência de chuvas distribuídas de maneira irregular de fevereiro a maio, temperatura média de $27,3{ }^{\circ} \mathrm{C}$ e máxima de $32,0^{\circ} \mathrm{C}$ ao longo do ano (Instituto de Desenvolvimento Sustentável e Meio Ambiente do Rio Grande do Norte - IDEMA, 2008). De acordo com Alvares et al. (2014), o clima da região segundo a classificação de Koppen é o BsW'h (quente seco).

Os solos predominantes da região são os latossolos vermelho amarelo eutrófico, com fertilidade de média a alta apresentando boas características de drenagem, a vegetação encontrada na região é de caatinga hiperxerófila, que possui características de regiões mais secas com predomínio de cactáceas e plantas de pequeno porte (IDEMA, 2008).

\subsection{Coleta e análise dos dados}

$\mathrm{Na}$ coleta dos dados foi adotado o método de amostragem aleatória, alocando-se 10 (dez) unidades amostrais de $20 \mathrm{~m} \times 20 \mathrm{~m}\left(400 \mathrm{~m}^{2}\right)$ seguindo o protocolo (REDE DE MANEJO FLORESTAL DA CAATINGA, 2005), totalizando uma área amostral de $4.000 \mathrm{~m}^{2}$. Para determinação do número ótimo de parcelas amostrais, foi utilizado o método de estabilização da curva do coletor (Figura 2).

Dentro das parcelas, foram inventariados todos os indivíduos arbóreos que apresentaram circunferência a altura do peito maior ou igual a seis centímetros $(C A P \geq 6 \mathrm{~cm})$. As variáveis mensuradas foram a circunferência a altura do peito (CAP), mensurada com fita métrica graduada em centímetros e a altura total (HT) com auxílio de vara telescópica graduada em metros.

As espécies encontradas, foram identificadas no campo por nome popular de acordo com as características dendrológicas e quando necessário realizou-se coleta de material botânico para identificação dos indivíduos através de consulta a literatura (LORENZI, 2009; SAMPAIO et al., 2005; GAMARRA- ROJAS et al., 2010; SIQUEIRA FILHO et al., 2009; FORZZA et al., 2012; SILVA et al., 2010; LIMA, 2012; MAIA, 2012) e especialistas. Para classificação das espécies encontradas foi adotado o sistema THE ANGIOSPERM PHYLOGENY GROUP (2016), classificando-as até o nível de espécies e família.

Após a coleta dos dados foram avaliados os parâmetros fitossociológicos de estrutura horizontal e vertical das espécies amostradas Felfili; Rezende (2003), e a diversidade florística de espécies através do Índice de Shannon-Weaver $\left(\mathrm{H}^{\prime}\right)$, de dominância de Simpson $(\mathrm{C})$ e equabilidade de Pielou (J').

Shannon-Weaver $\left(\mathrm{H}^{\prime}\right)$

$$
\mathbf{H}^{\prime}=\frac{\left[\mathrm{N} \cdot \operatorname{Ln}(\mathrm{N})-\sum_{\mathbf{i}=\mathbf{1}}^{\mathrm{s}} \mathbf{n}_{\mathbf{i}}\right]}{\mathbf{N}}
$$

Dominância de Simpson (C)

$$
S^{\prime}=\sum_{i=1}^{S} \frac{n j \cdot(n j-1)}{N \cdot(N-1)}
$$

Equabilidade de pielou (J')

$$
\mathbf{J}^{\prime}=\left(\frac{\mathbf{H}^{\prime}}{\mathrm{Hmax}}\right)
$$

em que: $\mathrm{S}=$ número total de espécies amostradas; $\mathrm{N}=$ número total de indivíduos amostrados; $\mathrm{ni}=$ número de indivíduos amostrados para a i-ésima espécie; $\mathrm{Ln}=$ logaritmo nepiteriano; $\mathrm{Hmax}=\mathrm{Ln}(\mathrm{S})$ = número total de espécies amostradas.

Além disso, foram elaboradas as distribuições diamétrica e hipsométrica. A distribuição diamétrica foi elaborada com o emprego de intervalos de classes de $3 \mathrm{~cm}$, já para a distribuição hipsométrica, os indivíduos foram estratificados utilizando-se intervalos de classes de $2 \mathrm{~m}$ de altura, sendo usadas as seguintes classes $\mathrm{H}<2,54,2,54 \leq \mathrm{H}<4,34$ e $\mathrm{H} \geq$ 4,34. Esse intervalo e essas classes foram gerados pelo software Mata Nativa baseado nas alturas coletadas em campo. 


\section{RESULTADOS}

Foram amostrados 694 indivíduos compreendendo 12 espécies distribuídas em 11 gêneros e 7 famílias botânicas (Tabela 1). A área apresentou uma densidade total de $1.927,78$ ind. ha ${ }^{-1}$. As famílias com maior riqueza foram Fabaceae e Euphorbiaceae, com 5 e 2 espécies, respectivamente, e juntas representaram aproximadamente $58,33 \%$ das espécies e 95\% dos indivíduos amostrados. As demais famílias foram representadas por uma única espécie cada (Tabela 2).

As espécies mais abundantes na área estudada foram Croton blanchetianus, Mimosa tenuiflora, Baubinia forficata, Mimosa ophthalmocentra e Poincianella pyramidalis, o conjunto dessas espécies representaram cerca de $92,93 \%$ da densidade total (ind.ha-1). Estas mesmas espécies obtiveram as maiores frequências relativas, com exceção da Mimosa tenuiflora, confimando assim, a predominância das demais no fragmento estudado. Vale salientar que Poincianella pyramidalis se destacou devido sua alta frequência, ocorrendo nas 9 parcelas analisadas.

Croton blanchetianus foi à espécie de maior destaque, por apresentar o maior número de indivíduos (321 ind.), e consequentemente, a maior densidade relativa $(46,25 \%)$ e a segunda maior frequência relativa $(14,04 \%)$. Ainda, foi a espécie que obteve a terceira maior dominância relativa (18,24\%), tornando-se, assim, a espécie com maiores valores de IVI e IVC do trecho amostrado.

A espécie Mimosa tenuiflora apresentou o segundo maior valor referente a densidade relativa $(18,44 \%)$ e a sexta maior frequência $(8,77 \%)$, assim como, o maior valor de dominância relativa $(26,94 \%)$, sendo a espécie com os segundos maiores valores de IVI e IVC da área.

As espécies Baubinia forficata, Mimosa ophthalmocentra, Poincianella pyramidalis e Aspidosperma pyrifolium também se destacaram na área de estudo, uma vez que obtiveram valores significativos para número de indivíduo, densidade relativa, frequência e dominancia relativa, além de representar 44,82\% e 40,04\% do IVI e IVC total da área, respectivamente.

O valor estimado para área basal foi de $5,53 \mathrm{~m}^{2}$. ha-1 (Tabela 2). As espécies que apresentaram maior área basal foram Croton blanchetianus, Mimosa tenuiflora e Poincianella pyramidalis, essas representaram 66,87\% da área basal de toda a área.

Quanto à diversidade estimada pelo índice de ShannonWeaver $\left(\mathrm{H}^{\prime}\right)$ para a área de estudo, o valor observado foi de
1,61 nats.ind ${ }^{-1}$ (Tabela 2). Com relação ao índice de Dominância de Simpson (C) que varia em uma escala de 0 a 1, foi encontrado nesse estudo um valor de 0,94 .

A suficiência amostral, representada pela curva coletora (Figura 2) estabilizou a partir da sexta unidade amostral, onde houve redução no número de novas espécies encontradas, ou seja, aos $2400 \mathrm{~m}^{2}$ os $100 \%$ das espécies inventariadas já haviam sido registradas. Logo após esse ponto houve a estagnação do número de espécies, indicando que a amostragem realizada foi satisfatória para a área em estudo, uma vez que atingiu o número mínimo de parcelas a ser utilizadas para caracterização da composição florística do fragmento estudado. Já para o índice de equabilidade de Pielou (J'), que variar de 0 a 1 , e quanto mais próximo maior a diversidade, o valor obtido no presente estudo foi de 0,65 , sendo considerado uma diversidade intermediária baseada nesse indíce.

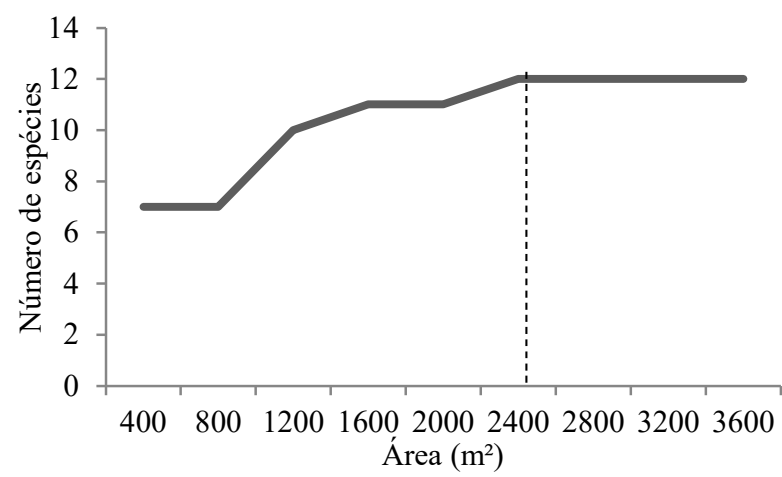

Figura 2. Representação gráfica da suficiência amostral das espécies inventariadas em um fragmento de caatinga em Serra do Mel, RN. Figure 2. Graphical representation of the sample sufficiency of the species inventoried in a caatinga fragment in Serra do Mel, RN.

Com relação a distribuição por classe de altura, pode-se constatar que o maior número de indivíduos foi encontrado na segunda classe $(2,54 \leq \mathrm{H}<4,34)$, correspondendo a cerca de $71 \%$ da população amostrada (Figura 3). A espécie que se destacou por apresentar indivíduos com os maiores valores de altura foi a Mimosa tenuiflora, essa espécie representou $50,92 \%$ do total de árvores presentes na maior classe de altura $(\mathrm{H} \geq 4,34)$.

Tabela 1. Relação das espécies arbustivo-arbóreas, encontradas em um trecho de caatinga no município de Serra do Mel, RN. Table 1. Relation of shrub-tree species, found in a patch of caatinga in the municipality of Serra do Mel, RN.

\begin{tabular}{lcc}
\hline \multicolumn{1}{c}{ Família / Espécie } & Nome Popular & Hábito \\
\hline $\begin{array}{c}\text { Apocynaceae } \\
\text { Aspidosperma pyrifolium Mart. \& Zucc. }\end{array}$ & Pereiro & Arbóreo \\
Burseraceae & Imburana Cambão & Arbóreo \\
Commiphora leptophloeos (Mart.) J.B.Gillett & & \\
Capparaceae & Feijão Bravo & Arbustivo \\
Cynophalla flexuosa (L.) J.Presl & Marmeleiro & Arbóreo \\
Euphorbiaceae & Pinhão Bravo & Arbustivo \\
Croton blanchetianus Baill. & & Arbóreo \\
Jatropha mollissima (Pohl) Bail. & Mororó & Arbóreo \\
Fabaceae & Jurema de Imbira & Arbóreo \\
Baubinia forficata Link & Jurema Preta & Arbóreo \\
Mimosa ophthalmocentra Mart. ex Benth & Jurema Branca & \\
Mimosa tenniflora (Willd.) Poir. & & Piptadenia stipulaceae (Benth.) Ducke
\end{tabular}




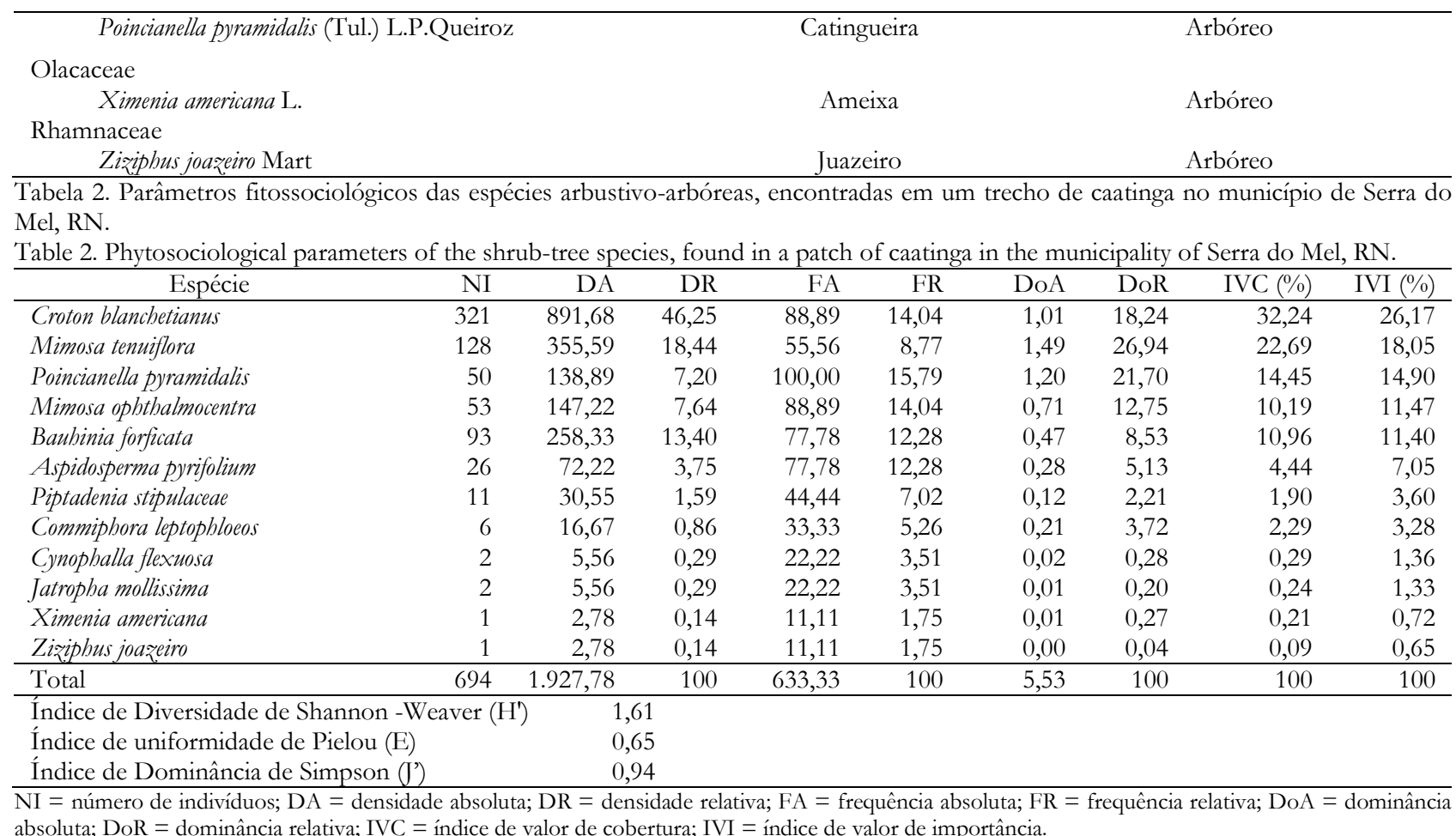

Foi observado uma maior concentração de indivíduos nas menores classes diamétricas, o que caracteriza a forma de J invertido (Figura 4), que é considerado o padrão típico de florestas naturais inequiâneas (DANTAS et al., 2010; ALVES et al., 2010). As duas primeiras classes diamétricas foram as que apresentaram maior número de indivíduos (438 e 151) equivalentes a aproximadamente $85 \%$ do total da amostra. A espécie que apresentou os maiores diâmetros foi Poincianella pyramidalis, representado cerca de $88 \%$ dos individuos presentes nas duas maiores classes diamétricas.

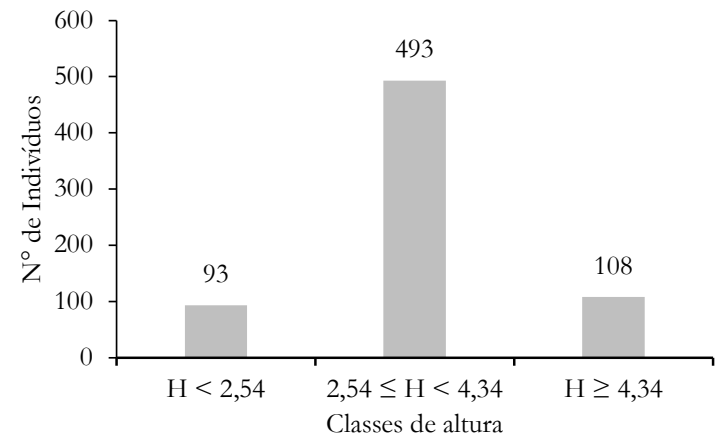

Figura 3. Número de indivíduos em classes de altura amostradas em um trecho de caatinga no município de Serra do Mel, RN.

Figure 3. Number of individuals in height classes sampled in a patch of caatinga in the municipality of Serra do Mel, RN.

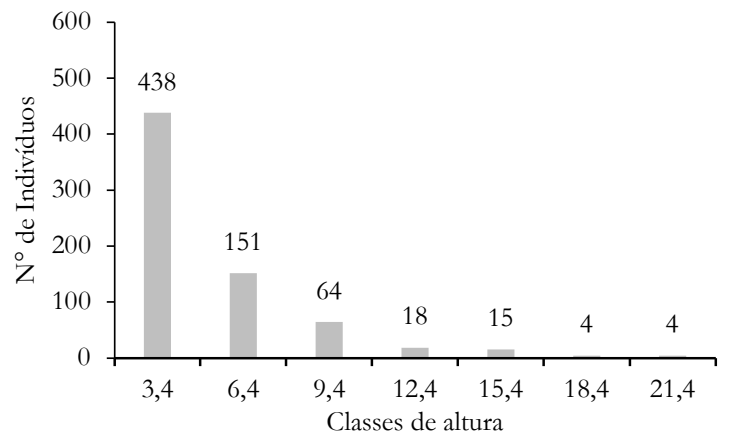

Figura 4. Distribuição diamétrica dos indivíduos amostrados em um trecho de caatinga no município de Serra do Mel, RN.

Figure 4. Diametric distribution of individuals sampled in a patch of caatinga in the municipality of Serra do Mel, RN.

\section{DISCUSSÃO}

Fabaceae e Euphorbiaceae foram às famílias botânicas mais representativas em número de espécies e indivíduos na área de estudo. Tais famílias são apontadas como as que apresentam o maior número de espécies na maioria dos levantamentos fitossociológicos na caatinga (FERRAZ et al., 2013; CALIXTO JÚNIOR; DRUMOND, 2014; LEITE et al., 2015; SANTOS et al., 2017a; SOUZA et al., 2017). As espécies dessas famílias botânicas são muito importantes para o bioma caatinga, pois em sua maioria apresentam elevado potencial forrageiro (CAMPOS et al. 2017), além disso os indivíduos da Fabaceae são capazes de fixar nitrogênio no solo em associação simbiótica com bactérias do gênero Rhizobium (ESPINDOLA et al., 2006; FREITAS et al., 2011).

As espécies Croton blanchetianus e Mimosa tenuiflora apresentaram um grande número de individuos, 321 e 128 ind.ha ${ }^{-1}$ respectivamente, ratificando a grande importância destas espécies pioneiras típicas da caatinga, como o observado por (SANTANA ; SOUTO 2006) e (LORENZI 
2009). Além disso, ambientes com elevada ocorrência dessas espécies está intimamente relacionada a antropização, indicando que a área encontra-se em estágios iniciais de sucessão secundária progressiva (PEREIRA et al. 2001; SABINO et al., 2016). Vale salientar também que tanto o Croton blanchetianus como a Mimosa tenuiflora, são espécies bem distribuidas em outras áreas de caatinga, sendo observadas em diversos levantamentos com percentuais de representantes significativos (FERNANDES et al., 2014; SABINO et al., 2016).

O valor estimado para área basal nesse estudo foi considerado baixo quando comparado ao observado em outros ambientes de caatinga, como por exemplo o encontrado por Ferraz et al. (2013), em um levantamento fitossociológico em área de caatinga no monumento natural Grota do Angico, em Sergipe, no qual foi usado o mesmo de critério de inclusão de espécies (CAP $>6 \mathrm{~cm}$ ) que calcularam um valor de $6,95 \mathrm{~m}^{2} . \mathrm{ha}^{-1}$. Assim como por Vasconcelos et al. (2017), em uma análise florística e fitossociológica em área de transição possuindo tanto espécies de cerrado quanto de caatinga, para fins de manejo florestal no município de São Francisco, PI, que acharam um valor de $13,08 \mathrm{~m}^{2} . \mathrm{ha}^{-1}$.

Em relação ao valor do índice de Shannon-Weaver, o resultado encontrado para o trecho de caatinga estudado é superior aos dos estudos realizados por Dantas et al. (2010), que encontraram um valor de 1,33 nats.ind ${ }^{-1} \mathrm{em}$ uma área de caatinga no município de Pombal-PB. Contudo, o presente trabalho apresentou resultados semelhantes aos encontrados por Andrade et al. (2005), de 1,51 e 1,43 nats.ind ${ }^{-1}$, os quais analisaram a cobertura de duas fitofisionomias de caatinga, com diferentes históricos de uso, no município de São João do Cariri, estado da Paraíba. Holanda et al. (2015) encontraram o valor de 1,50 nats.ind ${ }^{-1}$, em uma das remanescentes de caatinga avaliadas no município de Cajazeirinhas (PB). Lima ; Coelho (2018) estudando a fitossociologia e a estrutura de um fragmento florestal da caatinga no estado do Ceará, obteveram um valor de H' de 1,59 nats.ind $^{-1}$.

No entanto, o valor do índice de Shannon-Weaver $(1,61$ nats.ind $\left.{ }^{-1}\right)$ encontrado neste estudo é inferior aos observados por diversos autores que avaliaram diferentes área do Bioma caatinga, como: 2,54 nats.ind ${ }^{-1}$ (GUEDES et al., 2012), 1,92 nats.ind ${ }^{-1}$ e 1,76 nats.ind $^{-1}$ (SABINO et al, 2016) e 2,28 nats.ind $^{-1}$ (SANTOS et al., 2017a). Baseando-se nesses e em outros trabalhos desenvolvidos na caatinga, além de que esse índice pode variar de $1-4$ nats.ind $^{-1}$, pode-se dizer que o valor observado no presente estudo é considerado baixo.

De acordo com Dantas et al. (2010), é importante considerar a grande diversidade de fitofisionomias na caatinga e a variação nos processos de amostragem e parâmetros de inclusão de espécies de um trabalho para outro, o que resultará em variações entre os valores do índice de diversidade, levando em consideração que tal índice é muito importante para avaliar a riqueza de espécies de determinada área.

O valor do índice de equabilidade de Pielou $(0,65)$ nesse estudo foi considerado médio, indicando que a área apresenta uma uniformidade intermediária. Porém, quando comparado com outras áreas de caatinga esse índice foi superior ao obtido por Barbosa et al. (2012) de 0,57, em um fragmento de caatinga localizado no município de Arcoverde-PE utilizada para criação de ovinos em regime semiextensivo, e inferior aos observado por Santos et al. (2017b) de 0,77, em uma área de caatinga submetida a manejo florestal, localizada na propriedade Fazenda Nova, município de Desterro-PB.

O índice de Dominância de Simpson $(0,94)$ obtido nesse estudo indica uma baixa diversidade de espécie na área, resultados semelhantes foram encontrados por Guedes et al. (2012) de 0,96 e Leite et al. (2015) de 0,99. Já esse valor é superior aos encontrados por Marangon et al. (2013) de 0,84.

Com base na análise da distribuição em classes de diâmetros, e no levantamento florístico (Tabela 1). É possível afirmar que o fragmento de caatinga estudado é uma área de mata secundária, devido a grande maioria dos indivíduos inventariados se concentrarem nos primeiros centros de classes e muitas espécies pioneiras, secundárias iniciais e tardias. De acordo com Rodal et al. (2008), o padrão de distribuição diamétrica em $J$ invertido indica uma comunidade em processo de regeneração.

\section{CONCLUSÕES}

Fabaceae e Euphorbiaceae foram as famílias mais ricas em número de espécies e em número de indivíduos na área.

Croton blanchetianus, Mimosa tenuiflora, Baubinia forficata, Mimosa ophthalmocentra e Poincianella pyramidalis foram as espécies que assumiram maior importância na área de estudo sob os parâmetros fitossociológicos.

O fragmento estudado apresenta baixa diversidade de espécies se comparada com outros fragmentos florestais de caatinga já estudados.

\section{REFERÊNCIAS}

ALVARES, C. A.; STAPE, J. L.; SENTELHAS, P. C.; GONÇALVES, J. L. M.; GERD SPAROVEK, G. Köppen's climate classification map for Brazil. Meteorologische Zeit, Berlin, v.22, n.6, p.711-728. 2014. DOI: https://dx.doi.org/10.1127/09412948/2013/0507

ALVES, L. S.; HOLANDA, A. C.; WANDERLEY, J. A. C.; SOUSA, J. S.; ALMEIDA, P. G. Regeneração natural em uma área de caatinga situada no Município de PombalPB-Brasil. Revista Verde de Agroecologia e Desenvolvimento Sustentável, Pombal, v. 5, n. 2, p. 152-168, 2010.

ANDRADE, L. A.; PEREIRA, I. M.; LEITE, U. T.; BARBOSA, M. R. V. Análise da cobertura de duas fitofisionomias de caatinga, com diferentes históricos de uso, no município de São João do Cariri, estado da Paraíba. Cerne, Lavras, v. 11, n. 3, p. 253-262, 2005.

ARAÚJO FILHO, J. Manejo pastoril sustentável da caatinga. IICA, Brasilia (Brasil) Projeto Dom Helder Camara, Recife (Brasil) Projeto SEMEAR, Brasilia (Brasil) Associação Brasileira de Agroecologia, Rio Grande do Sul (Brasil), 2013. 204 p.

BARBOSA, M. D.; MARANGON, L. C.; FELICIANO, A. L. P.; FREIRE, F. J.; DUARTE, G. M. T. Florística e fitossociologia de espécies arbóreas e arbustivas em uma área de caatinga em Arcoverde, PE, Brasil. Revista Árvore, Viçosa, v. 36, n. 5, p. 851-858, 2012. DOI: https://dx.doi.org/10.1590/S0100-67622012000500007

BRASILEIRO, S. R. Alternativas de desenvolvimento sustentável no semiárido Nordestino: da degradação à conservação. Scientia Plena, v. 5, n. 5, p. 1-12, maio 2009. 
CALIXTO JÚNIOR, J. T.; DRUMOND, M. A. Estudo comparativo da estrutura fitossociológica de dois fragmentos de caatinga em níveis diferentes de conservação. Pesquisa Florestal Brasileira, Colombo, v. 34 , n. 80 , p. $345-355,2014$. DOI: http://dx.doi.org/10.4336/2014.pfb.34.80.670

CAMPOS, F. S.; GOIS, G. C.; VICENTE, S. L. A.; MACEDO, A.; MATIAS, A. G. S. Alternativa de forragem para caprinos e ovinos criados no semiárido. Nutritime Revista Eletrônica, Viçosa, v. 14, n. 2, p. 5004-5013, 2017.

CHAVES, A. D. C. G.; SANTOS, R. M. S.; SANTOS, J. O.; FERNANDES, A. A.; MARACAJÁ, P. B. A importância dos levantamentos florístico e fitossociológico para a conservação e preservação das florestas. Agropecuária Científica no Semiárido, Patos, v. 9, n. 2, p. 43-48, 2013.

DANTAS, J. G.; HOLANDA, A. C.; SOUTO, L. S.; JAPIASSU, A.; HOLANDA, E. M. Estrutura do componente arbustivo/arbóreo de uma área de caatinga situada no município de Pombal-PB. Revista Verde de Agroecologia e Desenvolvimento Sustentável, Pombal, v. 5, n. 1, p. 134-142, 2010.

ESPINDOLA, J. A. A.; GUERRA, J. G. M.; PERIN, A.; TEIXEIRA, M. G.; ALMEIDA, D. L. de; URQUIAGA, S.; BUSQUET, R. N. B. Bananeiras consorciadas com leguminosas herbáceas perenes utilizadas como coberturas vivas. Pesquisa Agropecuária Brasileira, Brasília, v. 41, n. 3, p. 415-420, 2006. DOI: https://dx.doi.org/10.1590/S0100204X2006000300007

FELFILI, J. M.; REZENDE, R. P. Conceitos e Métodos em Fitossociologia. Brasília: UnB, Departamento de Engenharia Florestal, 2003. 68 p. (Comunicações Técnicas Florestais).

FERNANDES, A. A.; MACARAJÁ, P. B.; HOLANDA, A. C.; SILVEIRA, D. C. Inventário do componente arbustivo-arbóreo com potencial apícola em uma área de caatinga no município de Condado-PB. Revista Verde de Agroecologia e Desenvolvimento Sustentável, Pombal, v. 9, n. 4, p. 27-35, 2014.

FERrAZ, R. C.; MELLO, A. A.; FERREIRA, R. A.; PRATA, A. P. N. Levantamento fitossociológico em área de caatinga no monumento natural grota do angico, Sergipe, Brasil. Revista Caatinga, Mossoró, v. 26, n. 3, p. 89-98, 2013.

FORZZA, R. C.; BAUMGRATZ, J. F. A.; BICUDO, C. E. M.; CARVALHO JR., A. A.; COSTA, A.; COSTA, D. P.; HOPKINS, M.; LETTMAN, P. M.; LOHMANN, L. G.; MAIA, L. C.; MARTINELLI, G.; MENEZES, M.; MORIM, M. P.; COELHO, M. A. N.; PEIXOTO, A. L.; PIRANI, J. R.; PRADO, J.; QUEIROZ, L.P.; SOUZA, V. C.; STEHMANN, J. R.; SYLVESTRE, L. S. B.; WALTER, M. T.; ZAPPI, D. (Coord.). Lista de Espécies da Flora do Brasil. Rio de Janeiro: Jardim Botânico, 2012.

FREITAS, A. D. S.; SILVA, T. O.; MENEZES, R. S. C.; SAMPAIO, E. V. S. B.; ARAÚJO, E. R.; FRAGA, V. S. Nodulação e fixação de nitrogênio por forrageiras da caatinga cultivadas em solos do semiárido paraibano. Revista Brasileira de Zootecnia, Viçosa, v. 40, n. 9, p. 1856-1861, 2011.

DOI: https://dx.doi.org/10.1590/S1516-35982011000900003
GAMARRA-ROJAS, C. F. L.; MESQUITA, A.C.; MAYO, S.; SOTHERS, C.; BARBOSA, M. R. V.; DALCIN, E. (Eds.). Banco de Dados de Plantas do Nordeste. Checklist das Plantas do Nordeste (versão 1.5).

GUEDES, R. S.; ZANELLA, F. C. V.; JÚNIOR COSTA, J. E. V.; SANTANA, G. M.; SILVA, J. A. Caracterização florístico-fitossociológica do componente lenhoso de um trecho de caatinga no semiárido paraibano. Revista Caatinga, Mossoró, v. 25, n. 2, p. 99-108, 2012.

HOLANDA, A. C.; LIMA, F. T. D.; SILVA, B. M. DOURADO, R.G.; ALVES, A. R. Estrutura da vegetação em remanescentes de caatinga com diferentes históricos de perturbação em Cajazeirinhas (PB). Revista Caatinga, Mossoró, v. 28, n. 4, p. 142- 150, 2015.

IDEMA_INSTITUTO DE DESENVOLVIMENTO SUSTENTÁVEL E MEIO AMBIENTE DO RIO GRANDE DO NORTE; Perfil do seu município Serra do Mel. Rio Grande do Norte, 2008. Disponível em:

<http://adcon.rn.gov.br/ACERVO/idema/DOC/DO C000000000013820.PDF>. Acesso em: 25 de abr. de 2019.

LEITE, J.A.N.; ARAÚJO, L.V.C.; ARRIEL, E.F.; CHAVES, L.F.C.; NÓBREGA, A.M.F. Análise quantitativa da vegetação lenhosa da Caatinga em Teixeira, PB. Pesquisa Florestal Brasileira, Colombo, v. 35, n. 82, p. 89-100, 2015.2 DOI: http://dx.doi.org/10.4336/2015.pfb.35.82.584

LIMA, B. G. Caatinga: espécies lenhosas e herbáceas. Mossoró: Ed. UFERSA, 2012. 316 p.

LIMA, B.G.; COELHO, M.F.B. Fitossociologia e estrutura de um fragmento florestal da caatinga, Ceará, Brasil. Revista Ciência Florestal, Santa Maria, v. 28, n. 2, p. 809-819, 2018.2 DOI: http://dx.doi.org/10.5902/1980509832095

LORENZI, H. Árvores brasileiras: manual de identificação e cultivo de plantas arbóreas nativas do Brasil. 3. ed. Nova Odessa: Instituto Plantarum de Estudos da Flora, 2009. 2 v. 384 p.

MAIA, G. N. Caatinga: árvores e arbustos e suas utilidades. 2. ed. Fortaleza: Printcolor Gráfica e Editora, 2012. 413 p.

MARANGON, G. P.; FERREIRA, R. L. C.; SILVA, J. A. A.; LIRA, D. F. S. S.; SILVA, E. A.; LOUREIRO, G. H. Estrutura e padrão espacial da vegetação em uma área de caatinga. Revista Floresta, Curitiba, v. 43, n. 1, p. 83-92, 2013. DOI: https://doi.org/10.5380/rf.v43i1.27807

MMA_MINISTÉRIO DO MEIO AMBIENTE. Monitoramento do bioma caatinga. Brasília: MMA, 2019. Disponível em: <http://www.mma.gov.br/estruturas/sbf_chm_rbbio/ _arvos/relatrio_tcnico_caatinga_72.pdf $>$ Acesso em: 25 de abr. de 2019.

PEREIRA, I. M.; ANDRADE, L. A.; COSTA, J. R. M.; DIAS, J. M. Regeneração natural em um remanescente de caatinga sob diferentes níveis de perturbação, no Agreste Paraibano. Acta Botânica Brasilica, São Paulo, v. 15, n. 3, p. 413-426, 2001. https://doi.org/10.1590/S010233062001000300010

REDE DE MANEJO FLORESTAL DA CAATINGA. Protocolo de Medições de Parcelas Permanentes. Recife: Associação de Plantas do Nordeste; Brasília: MMA/PNF/PNE, 2005. 30 p. 
RODAL, M. J. N.; COSTA, K. C. C.; SILVA, N. C. B. L. Estrutura da vegetação caducifólia espinhosa (Caatinga) de uma área do sertão central de Pernambuco. Hoehnea, São Paulo, v. 35, n. 2, p. 209-217. 2008. DOI: https://doi.org/10.1590/S2236-89062008000200004

RODAL, M. J. N.; SAMPAIO, E. V. S. B., FIGUEIREDO, M. A. Manual sobre métodos florísticos e fitossociológicos. Brasília: Sociedade Botânica do Brasil, 1992. $24 \mathrm{p}$.

SABINO, F. G. S.; CUNHA, M. C. L.; SANTANA, G. M. Estrutura da Vegetação em Dois Fragmentos de Caatinga Antropizada na Paraíba. Floresta e Ambiente, v. 23, n. 4, p. 487-497, 2016. DOI: http://dx.doi.org/10.1590/2179-8087.017315

SAMPAIO, E. V. S. B.; PAREYN, F. G. C.; FIGUEIRÔA, J. M.; SANTOS JUNIOR, A. G. S. (Eds.). Espécies da flora nordestina de importância econômica potencial. Recife: Associação Plantas do Nordeste, 2005. $331 \mathrm{p}$.

SANTANA, J. A. S.; SOUTO, J. S. Diversidade e estrutura fitossociológica da caatinga na estação ecológica do Seridó-RN. Revista de Biologia e Ciências da Terra, João Pessoa, v. 6, n. 2, p. 232-242, 2006.

SANTOS, W. S.; HENRIQUES, G. N.; SANTOS, W. S.; RAMOS, G. G.; VASCONCELOS, G. S.; VASCONCELO, A. D. M. Análise florísticafitossociológica e potencial madeireiro em área de caatinga submetida a manejo florestal. Agropecuária Científica no Semiárido, Patos, v.13, n.3, p.203-211, 2017b.

SANTOS, W. S.; SOUZA, M. P.; NÓBREGA, G. F. Q.; MEDEIROS, F. S.; ALVES, A. R.; HOLANDA, A. C. Caracterização florístico-fitossociológica do componente lenhoso em fragmento de caatinga no município de Upanema-RN. Nativa, Sinop, v. 5, n. 2, p. 85-91, 2017 a. DOI: http://dx.doi.org/10.5935/2318-7670.v05n02a02
SILVA, J. S.; SALES, M. F.; GOMES, A. P. S.; CARNEIROTORRES, D. S. Sinopse das espécies de Croton L. (Euphorbiaceae) no estado de Pernambuco, Brasil. Acta Botânica Brasílica, São Paulo, v. 24, n. 2, p. 441-453, 2010. DOI: http://dx.doi.org/10.1590/S010233062010000200015

SIQUEIRA FILHO, J. A.; SANTOS, A. P. B.; NASCIMENTO, M. F. S.; ESPIRITO SANTO, F. S. Guia de Campo de Árvores da Caatinga. Petrolina: Editora e Gráfica Franciscana Ltda., 2009. 64 p.

SOUZA, M. P.; COUTINHO, J. M. C. P.; SILVA, L. S.; AMORIM, F. S.; ALVES, A. R. Composição e estrutura da vegetação de caatinga no sul do Piauí, Brasil. Revista Verde de Agroecologia e Desenvolvimento Sustentável, Pombal, v. 12, n. 2, p. 210-217, 2017. DOI: https://dx.doi.org/10.18378/rvads.v12i2.4588

THE ANGIOSPERM PHYLOGENY GROUP; CHASE, M. W.; CHRISTENHUSZ, M. J. M.; FAY M. F.; BYNG J. W.; JUDD, W. S.; SOLTIS, D. E.; MABBERLEY, D. J.; SENNIKOV, A. N.; SOLTIS, P. S.; STEVENS, P. F. An update of the Angiosperm Phylogeny Group classification for the orders and families of flowering plants: APG IV, Botanical Journal of the Linnean Society, v. 181, n. 1, p. 1-20, 2016. DOI: https://dx.doi.org/10.1111/boj.12385

VASCONCELOS, A. D. M.; HENRIQUES, I. G. N.; SOUZA, M. P.; SANTOS, W. S.; SANTOS, W. S.; RAMOS, G. G. Caracterização florística e fitossociológica em área de Caatinga para fins de manejo florestal no município de São Francisco-PI. Agropecuária Científica no Semiárido, v. 13, n. 4, p. 329-337, 2017.2 DOI: http://dx.doi.org/10.30969/acsa.v13i4.967 